\title{
VENCENDO A PAIXÃO E A EMOÇÃO NOS CONFLITOS FAMILIARES: A CONCILIAÇÃO E A MEDIAÇÃO COMO SOLUÇÃO PARA OS LITÍGIOS NA ẢREA DE FAMÍLIA
}

\author{
WINNING THE PASSION AND EMOTION IN FAMILY CONFLICTS: \\ RECONCILIATION AND MEDIATION AS A VIABLE SOLUTION TO \\ DISPUTES INVOLVING FAMILY LAW
}

\begin{abstract}
${ }^{1}$ José Sebastião de Oliveira
${ }^{2}$ Humberto Luiz Carapunarla

\section{RESUMO}

Pretende-se travar, com o presente trabalho, uma análise acerca da importância dos institutos da conciliação e mediação nos litígios na área de família, como forma de pacificação social, máxime ser comum aos litigantes, em casos tais, o animus alterado. Assim, a conciliação tem como escopo a solução rápida e eficaz dos litígios, cabendo à mediação um objetivo maior, qual seja a pacificação do conflito familiar. Tem por finalidade despertar nas das partes o interesse na solução do problema e na reorganização familiar, sem perder de vista a posterior convivência, inerente ao seio familiar.
\end{abstract}

Palavras-chave: Direito de família, Conflitos, Conciliação, Mediação, Pacificação familiar

\begin{abstract}
The scope of the present study is to analyse the importance of the institutes of reconciliation and mediation in disputes involving family law, as a way towards social pacification, even thow it is common that parties, in such cases, come in hot headed. The reconciliation method has its focus set on the rapid and effective resolution of disputes, while the mediation method has a larger goal, which is the pacification of family conflict. This second method (mediation) aims to arouse the interest of the parties in solving the problem of family reorganization
\end{abstract}

Keywords: Family right, Conflicts, Conciliation, Mediation, Family peace

\footnotetext{
${ }^{1}$ Pós-Doutorado em Direito pela Universidade de Lisboa - UL, (Portugal). Professor do Centro Universitário de Maringá - UNICESUMAR, Paraná. E-mail: drjso@brturbo.com.br (Brasil)

${ }^{2}$ Mestrando em Ciências Jurídicas pelo Centro de Ensino Superior de Maringá - CESUMAR, Paraná, (Brasil). Professor titular da Escola da Magistratura do Paraná, Curitiba, Paraná. E-mail: carapu@uol.com.br
} 


\section{INTRODUÇÃO}

Muito se discute a respeito da melhor técnica para solução dos conflitos familiares, uma vez que a sentença do magistrado está longe de resolver a questão e manter a harmonia familiar entre os contendores, na maioria dos casos. Tudo porque a paixão e a emoção das partes se misturam ao objeto do litígio, o que é normal, nos litígios entre cônjuges, companheiros e parentes.

Assim, em muitos casos a sentença se apresenta como solução do litígio, mas não consegue apaziguar as partes que, na maioria das vezes tem que continuar a conviver, situação que se apresenta como um suplício, principalmente porque os litígios de família normalmente não apresentam um vencedor, mas partes que tem cindidos seus direitos, como é o caso das ações de guarda, visitação e alimentos de filhos, entre outras.

E, nesse contexto, os institutos da conciliação e mediação amenizam a consequência, quando não conseguem resolver - e apaziguar - totalmente a questão. Daí a importância de proporcionar às partes a possibilidade de solução por intermédio de tais institutos.

Dessa forma, com o escopo de demonstrar que tais institutos são os meios mais apropriados de solução dos conflitos familiares, bem como, devem preceder a todos os processos, restando uma decisão judicial somente para as exceções, é que serão adiante lançados os conceitos e apuradas as diferenças da conciliação e da arbitragem, buscando demonstrar em que casos um ou outro instituto - ou os dois - deverão ser aplicados.

De outra forma - e como consequência -, tem-se ainda que a conciliação e a mediação prévia, através de um procedimento simples e rápido, acabam por impedir que as partes se sujeitem a procedimentos desgastantes e, por vezes, vexatórios, inerentes à instrução processual, o que também se traduz numa forma de alento aos envolvidos, resguardando suas dignidades.

A pesquisa realizada para elaboração deste trabalho cientifico consistiu na utilização de métodos de procedimento histórico e comparativo; métodos jurídicos, interpretativos, exegéticos e sistemáticos. Tudo, com o olhar voltado à pesquisa documental e bibliográfica atinentes ao tema, tanto em trabalhos já desenvolvidos no Brasil como em outros países com mais tradição na utilização da conciliação e arbitragem como meio de solução de conflitos.

\section{EMOÇÃO E PAIXÃO NOS CONFLITOS FAMILIARES}

De acordo com Holanda (2004, p. 38), a emoção (em conceituação ampla), "é uma experiência subjetiva, associada a temperamento, personalidade e motivação. A palavra deriva do latim emovere, onde o $e$ - (variante de $e x$-) significa 'fora' e movere significa 'movimento"'. 
A emoção é estado anímico súbito, repentino, arrebatador e, ao mesmo tempo fulgaz, passageiro, uma experiência afetiva que aparece de maneira brusca em razão de uma experiência excitante, que provoca reações motoras e glandulares, além de alterar o estado afetivo. É um impulso neural que move o organismo para a ação.

As psicólogas Lukenya Laize Silva da Cunha e Regilene Ferreira da Silva (apud PINTO, 2001), citando o psicólogo português Amâncio da Costa Pinto, destacam que:

\begin{abstract}
A emoção é uma experiência subjetiva que envolve a pessoa toda, a mente e o corpo. É uma reação complexa desencadeada por um estímulo ou pensamento e envolve reações orgânicas e sensações pessoais. É uma resposta que envolve diferentes componentes, nomeadamente uma reação observável, uma excitação fisiológica, uma interpretação cognitiva e uma experiência subjetiva.
\end{abstract}

Por outro lado, também em conceito lato, pode-se dizer que paixão ${ }^{1}$, segundo Holanda (2010, p. 67), "é um termo aplicado a um sentimento muito forte em relação a uma pessoa, objeto ou tema. A paixão é uma emoção intensa convincente, um entusiasmo ou um desejo sobre qualquer coisa". Ao contrário da emoção pura, é um sentimento lento, que se perdura no tempo, alojando-se no subjetivo da pessoa de forma duradoura.

Aliás, é justamente a questão temporal que se apresenta como diferenciador básico entre a emoção e a paixão. Neste sentido, com maestria, o jurista Nélson Hungria (1949, p. $523)$, ponderou que:

A emoção é uma descarga nervosa subitânea, que por sua breve duração, se alheia aos plexos superiores que coordenam a conduta ou não atinge o plano neopsíquico de que fala Patrizi. A paixão é, por assim dizer, a emoção em estado crônico, perdurando surdamente como um sentimento profundo e monopolizante (amor, ódio, vingança, fanatismo, despeito, avareza, ambição, ciúme). A emoção dá e passa; a paixão permanece alimentando-se de si própria. Mas a paixão é como o borralho que a um sopro, volta a ser fogo crepitante, retornando a ser estado emocional agudo.

E tais sentimentos, tão bem delineados pelas citações expostas, estão enleados nas questões de família, que não raramente desabrocham em ações impensadas e perigosas, muitas vezes em nome do amor, que também não deixa de ser uma forma de paixão que pode levar à violenta emoção, que é, às vezes, a exteriorização de outras paixões mais duradouras.

Aliás, segundo o minidicionário Aurélio (2010, p. 118), "amor é um sentimento que predispõe alguém a desejar o bem de outrem; a proteger ou a conservar a pessoa pela qual se sente afeição; devoção extrema". Fernando de Alencar Pedroso (1995, p. 95) informa que: "São emoções: o medo, a alegria, a ira, a vergonha, a surpresa, o prazer erótico, o espanto, a aflição, o entusiasmo, a euforia. E são paixões: o amor, o ódio, a avareza, o fanatismo, a ambição, a inveja, o ciúme, o patriotismo, a cupidez".

1 Do latim tardio passio -onis, derivado de passus, particípio passado de pati (sofrer). 
É certo, portanto, que as relações familiares envolvem sentimentos de emoção e paixão, podendo levar o sujeito envolvido a extremas atitudes, razão pela qual cabe ao aplicador do direito criar meios para vencer tais sentimentos de maneira a solucionar o problema apresentado, sem perder de vista o objetivo maior: a pacificação e a vida harmoniosa familiar. É esta, pois, a razão do presente estudo.

\section{CONCILIAÇÃO E MEDIAÇÃO: CONCEITOS E DIFERENÇAS}

Conciliação é uma forma de solução de conflitos em que um terceiro, o conciliador ${ }^{2}$, através de técnicas próprias, tenta levar os envolvidos a um acordo. Sua função é de orientação e ajuda, sendo que a solução deve atender aos interesses dos dois lados e achar um ponto de equilíbrio entre interesses divergentes entre as partes litigantes.

Segundo o dicionário Aurélio da Língua Portuguesa (2004, p. 26), a palavra conciliação, derivada do latim conciliatione, significa o "ato ou efeito de conciliar, ou seja, pôr em harmonia; pôr de acordo; congraçar (reatar relações, fazer as pazes); reconciliar (tornar amigos); aliar, unir, combinar; atrair, captar, conseguir ficar em paz, em harmonia, consigo mesmo".

Roberto Portugal Bacellar (2012, p. 66), com relação ao tema, aduz que:

Definimos a conciliação (nossa posição) como um processo técnico (não intuitivo), desenvolvido, pelo método consensual, na forma autocompositiva, em que terceiro imparcial, após ouvir as partes, orienta-as, auxilia, com perguntas, propostas e sugestões a encontrar soluções (a partir da lide) que possam atender aos seus interesses e as materializa em um acordo que conduz à extinção do processo judicial.

O jurista Ivan Ruiz (2005, p. 59) aponta a natureza jurídica da conciliação como sendo contratual híbrida, pois se trata de meio de solução de conflito, mas por vontade das próprias partes, no âmbito do processo, ou seja, não há pronunciamento judicial (decisão, julgamento), dependendo a solução da controvérsia, da vontade dos envolvidos ${ }^{3}$.

A despeito de posições em contrário, para nós, segundo o Código de Processo Civil, a conciliação seria somente endoprocessual, pois ela, na forma como vem posta, é sempre ato do juiz. E este, no aspecto jurisdicional, somente exerce suas funções no processo, pelo que não se poderia falar em conciliação extrajudicial. O que a doutrina entende como conciliação extrajudicial trata-se da mediação.

\footnotetext{
${ }^{2}$ Pessoa que procura apaziguar os conflitos e diante desse cargo, deverá estar preparado para os desafios que enfrentará nos diferentes casos apresentados, portanto, deverá desenvolver algumas habilidades.

${ }^{3}$ Segundo o autor, a conciliação não é - e não se confunde - com a jurisdição, onde a solução do conflito é imposta por ato de terceiro, no caso, do Estado-juiz, com a decisão.
} 
Já a mediação é tida como uma forma de solução de conflitos em que um terceiro neutro e imparcial - o mediador ${ }^{4}$-, também com técnicas próprias, auxilia as partes a entender o conflito e buscar a solução, através de conversas, ponderações e reflexões. A decisão para o caso concreto, caso frutífera a mediação, é levada a efeito pelas próprias partes, sendo que o mediador atua apenas como um facilitador.

Araken de Assis (2015, p. 96) destacando como escopo primordial da mediação o esforço no sentido de facilitar a comunicação entre os litigante, diz o seguinte:

Talvez a melhor diretriz recaia nos elementos intrínsecos da atividade de aproximação e promoção do diálogo dos desavindos. O mediador abstém-se de emitir opinião própria acerca das reclamações recíprocas. Limita-se a incentivar e auxiliar os desavindos. Daí a importância de envolver áreas paralelas à jurídica utilizando pessoas cujo especial saber os auxilie a interpretar emoções e arredar as barreiras psicológicas que predeterminam o contraste de posições. A mediação representa o veículo da justiça restauradora. Ela desanuvia os espíritos, restabelece relações e apazigua o sofrimento dos litigantes.

Atualmente, a ideia é criar centrais e câmaras de conciliação, onde a mediação e a conciliação serão feitas simultaneamente, notadamente em casos de problemas de ordem pessoal, onde impera a emoção e a paixão (sentimentos de raiva, vingança, intolerâncias, entre outros), para que possa haver a pacificação do problema, ou seja, resolver a questão, mas também aproximar as partes para que a convivência posterior, sempre presente em casos tais, possa ser possível da melhor maneira.

Tem-se que a conciliação é mais adequada para a solução de casos circunstanciais, ou seja, onde não exista qualquer vínculo anterior entre as pessoas, vínculo este havido com o fato que originou o litígio e que, após a solução, certamente tal vínculo não continuará, como no caso de um acidente de trânsito ou de uma compra e venda malsucedida. Indispensável a cooperação mútua para um bom desiderato da ação judicial proposta.

A mediação, de seu turno, tem como objetivo, além de resolver a questão da melhor maneira para as partes, manter e preservar os vínculos já existentes, uma vez que, como já salientado, normalmente tal vínculo continuará existindo após a solução da questão, como no caso das questões de família, quando envolvem patrimônio, filhos, entre outros $\operatorname{casos}^{5}$. Aliás, neste sentido, oportuno destacar o que jurista João Roberto da Silva (2004, p. 24) doutrina:

\footnotetext{
${ }^{4}$ Pessoa imparcial e eleita pelas partes de livre acordo, age como um "facilitador", auxiliando-as na solução de suas controvérsias sobre determinado assunto. Note-se que, diferente do que ocorre no instituto da arbitragem, em que o árbitro exerce o controle da situação, na mediação as partes é que decidem o litígio, levando em consideração as opiniões do mediador, que tem habilidade e técnica para fazer com que elas negociem da melhor maneira. Sendo assim, o mediador só poderá participar do litígio para delinear os limites deste, fazendo com que as partes, por si só, cheguem a um acordo que as favoreça.

${ }^{5}$ Em alguns países, como Estados Unidos e Japão, é comum os empregados reclamarem seus direitos trabalhistas e resolverem o litígio pela mediação, sem prejudicar a relação de emprego.
} 
Que sempre que as partes estão envolvidas em relações multicomplexas, isto é, relações de múltiplo vínculo (opostas às relações circunstanciais, de vínculo único que se estabelecem entre estranhos), a continuidade das relações por sobre o conflito tende a criar um peso estrutural a cujo equilíbrio só a conciliação pode adequar.

O Conselho Nacional de Justiça (CONSELHO NACIONAL DE JUSTIÇA, 2016) diferencia os institutos, conceituando-os da seguinte maneira:

\begin{abstract}
A Mediação é uma forma de solução de conflitos na qual uma terceira pessoa, neutra e imparcial, facilita o diálogo entre as partes, para que elas construam, com autonomia e solidariedade, a melhor solução para o problema. Em regra, é utilizada em conflitos multidimensionais, ou complexos. A Mediação é um procedimento estruturado, não tem um prazo definido, e pode terminar ou não em acordo, pois as partes têm autonomia para buscar soluções que compatibilizem seus interesses e necessidades. A conciliação é um método utilizado em conflitos mais simples, ou restritos, no qual o terceiro facilitador pode adotar uma posição mais ativa, porém neutra com relação ao conflito e imparcial. É um processo consensual breve, que busca uma efetiva harmonização social e a restauração, dentro dos limites possíveis, da relação social das partes. As duas técnicas são norteadas por princípios como informalidade, simplicidade, economia processual, celeridade, oralidade e flexibilidade processual. Os mediadores e conciliadores atuam de acordo com princípios fundamentais, estabelecidos na Resolução 125/2010: confidencialidade, decisão informada, competência, imparcialidade, independência e autonomia, respeito à ordem pública e às leis vigentes, empoderamento e validação".
\end{abstract}

Ainda, o CNJ editou a Resolução no 125/2010 (CONSELHO NACIONAL DE JUSTIÇA, 2016), que dispõe sobre a Política Judiciária Nacional de tratamento adequado dos conflitos de interesses no âmbito do Poder Judiciário.

O Pacto Republicano do Estado Brasileiro, que visa um sistema judicial mais acessível, ágil e efetivo e, para conseguir atingir os objetivos dispostos, é outro dispositivo que retrata a conciliação e a mediação. Um de seus compromissos é "fortalecer a mediação e a conciliação, estimulando a resolução de conflitos por meios autocompositivos, voltados à maior pacificação social e menor judicialização" (PRESIDÊNCIA DA REPÚBLICA, 2016).

A doutrina aponta várias vantagens da conciliação e mediação, das quais destacamos, neste trabalho, aquelas apontadas por Tayna Xavier Arantes Bueno (2016):

1. Solução rápida e barata do problema: um processo que muitas vezes dependeria de produção de provas, de realização de perícia, de oitiva de testemunhas, é resolvido mediante a construção de um acordo por ambas as partes, com concessões recíprocas, evitando ainda recursos, incidentes processuais e execução, enfim, a tão combatida morosidade processual;

2. Solução mais satisfatória para as partes que estão litigando: uma decisão que é construída pelas duas partes é muito mais aceita do que uma decisão imposta por um juiz, onde sempre vai existir um insatisfeito que vai buscar um recurso que adia o cumprimento da decisão. Pode inclusive haver a continuidade da relação entre as partes após a obtenção conciliatória. Por tal, fala-se também em "solução pacífica". 
3. Desafogamento das varas judiciais: a conciliação evita o processo, sendo que em casos tais os juízes têm condições de dedicar a atenção para casos mais complexos, nos quais o acordo é inviável.

Owen Fiss (2004), doutrinador e jurista norte-americano, no entanto, fala sobre as desvantagens do acordo em juízo ${ }^{6}$. Para ele:

$\mathrm{O}$ acordo seria uma espécie de rendição às condições da sociedade de massa que não deveria ser encorajado ou valorizado. Logo a primeira desvantagem dos acordos está na sua própria origem, já que a sua celebração, na maioria dos casos, é impulsionada por vários fatores negativos, quais sejam, a morosidade da justiça, os elevados custos processuais, a má-qualidade da prestação jurisdicional (em razão do excesso de demandas e da falta de infraestrutura adequada ao Poder Judiciário), e, por fim, as repercussões sociais advindas ao longo do trâmite processual. Como consequência, há a celebração de acordos lesivos a uma das partes ou até a ambas as partes.

Em que pese o entendimento esposado, discorda-se com as desvantagens apontadas por aquele doutrinador, principalmente diante da grande possibilidade de informações hoje possíveis a qualquer pessoa, além do devido acompanhamento de profissionais. Ao contrário, se entende que os institutos da conciliação e mediação possibilitam justamente evitar tais problemas $^{7}$, apresentando-se como melhores soluções do que o litígio, que não tem tempo para o seu encerramento, prolongando-se a angústia das partes indefinidamente.

\section{PRINCÍPIOS NORTEADORES DOS INSTITUTOS DA CONCILIAÇÃO E MEDIAÇÃ̃o}

Em célebre conceituação de princípios, o jurista Celso Antonio Bandeira de Mello (1991, p. 230) doutrina que:

Princípio é, por definição, mandamento nuclear de um sistema, verdadeiro alicerce dele, disposição fundamental que se irradia sobre diferentes normas compondo-lhes o espírito e servindo de critério para sua exata compreensão e inteligência, exatamente por definir a lógica e a racionalidade do sistema normativo, no que lhe confere a tônica e lhe dá sentido harmônico.

\footnotetext{
${ }^{6}$ Ao mencionar as repercussões sociais como um dos fatores negativos que dão ensejo à celebração "forçada" de acordos, Owen Fiss se refere às pressões externas que influenciam o comportamento das partes durante a tramitação processual. Isto ocorre, por exemplo, no caso em que o demandado teme que durante a instrução probatória venha a ser desvendado um fato inconveniente ou ilícito estranho à lide; pode-se também citar como repercussão social, a premente necessidade da parte autora de receber um crédito para saldar uma dívida, ou para assegurar alimentos ou pagamento de serviços de saúde para um membro da família.

${ }^{7}$ Segundo Marina Nunes Vieira, no Direito Comparado encontramos inúmeros países que se utilizam do método da conciliação como uma forma mais pacífica, menos informal para a resolução de conflitos sem que seja necessária a abertura de um processo judicial e todas as inconveniências que ele traz consigo. Nos Estados Unidos há a Smal Claims Courts', que se aplica aos conflitos de menor valor e existem em todos os Estados da Federação; em Portugal há os Julgados de Paz, Tribunais extrajudiciais onde estão presentes juízes leigos e juízes de paz; em França há o Juges de Proximité, que se aplica às pequenas causas e contravenções penais, e são no total de 3.300, metade da jurisdição é por eles exercida; no Japão há a cultura milenar da conciliação. In: VIEIRA, Marina Nunes. Conciliação: simples e rápida solução de conflitos. Disponível em: <http://blog.newtonpaiva.br/direito/wpcontent/uploads/2012/08/PDF-D13-05.pdf>. Acesso em: 28 mar. 2016.
} 
Dentro desse conceito, o Conselho Nacional de Justiça, na Resolução no 125, de 29 de novembro de 2010 (CONSELHO NACIONAL DE JUSTIÇA, 2016), ditou, como princípios da conciliação e da mediação, os seguintes:

1. Princípio da Neutralidade e Imparcialidade: o conciliador deve manter-se imparcial diante das partes. Deve agir com ausência de favoritismo, preferência ou preconceito, assegurando que valores e conceitos pessoais não interfiram no resultado do trabalho, compreendendo a realidade dos envolvidos no conflito e jamais aceitando qualquer espécie de favor ou presente;

2. Princípio da Aptidão Técnica e Competência: o conciliador deve possuir qualificação que o habilite à atuação judicial, observada a reciclagem periódica obrigatória para formação continuada. Ainda, devem deixar que a conciliação corra de instinto para que as partes se sintam seguras e confiantes no condutor da conciliação;

3. Princípio da Independência e Autonomia: as partes têm sua autonomia preservada, cabendo a elas decidirem seus conflitos sem interferência do Estado. Ainda, o conciliador deve atuar com liberdade, sem sofrer qualquer pressão interna ou externa, sendo permitido recusar, suspender ou interromper a sessão, se ausentes as condições necessárias para seu bom desenvolvimento, tampouco havendo dever de redigir acordo ilegal ou inexequível;

4. Da Decisão Informada: as partes têm o direito de receber informações quanto aos seus direitos e ao contexto fático no qual está inserido e que será objeto de análise;

5. Princípio da Simplicidade: o procedimento deve ser simples e claro com o fim de deixar as partes à vontade para melhor se manifestarem ou expressarem seus interesses;

6. Da Confidencialidade: deve haver sigilo entre as partes e principalmente entre o conciliador, salvo autorização expressa das partes, violação à ordem pública ou às leis vigentes;

7. Princípio do Respeito à Ordem Pública e às Leis Vigentes: eventual acordo entre os envolvidos não pode violar a ordem pública e nem contrariar as leis vigentes;

8. Princípio "Pax Est Querenda": também conhecido por princípio da normalização do conflito, exige que o conciliador deixe as partes tranquilas, pois se a desavença é um produto natural da sociedade, também a solução destes embates é um produto natural da sociedade;

9. Princípio do Empoderamento: tem caráter pedagógico para formar o cidadão em um futuro agente de resolução de conflitos a partir da conciliação, ou seja, estimular os interessados a aprenderem a melhor resolverem seus conflitos futuros em função da experiência de justiça vivenciada na autocomposição; e

10. Princípio da Validação: dever de estimular os interessados perceberem-se reciprocamente como serem humanos merecedores de atenção e respeito. 
Além dos Princípios citados, devem ser observados outros valores, quais sejam:

Respeito: que é o reconhecimento da diversidade, possibilitando a consistência das diferenças culturais, sociais e raciais;

Ética: a conduta deve ser pautada pela dignidade, honestidade e respeito à dignidade das pessoas;

Compromisso: deve haver responsabilidade e comprometimento contínuo com a promoção da paz social; e

Responsabilidade Social: que é o benefício às comunidades, oferecendo acesso à solução de conflitos com o amparo do Poder Judiciário, que em última análise é o acesso à Justiça, visando a celeridade dos litígios.

\section{REGRAS E TÉCNICAS DE CONCILIAÇÃO E MEDIAÇÃO}

Adevanir Tura (2007, p. 13), tratando sobre as regras e técnicas da conciliação e mediação, aduz que "o mediador tem como função uma série ordenada de atos de trajetória informal, a sua atuação deverá ocorrer de forma neutra, absolutamente imparcial e visando a facilitar a solução do conflito apresentado pelas partes".

Já Maria de Narazeth Serpa (1997, p. 162), detalhando mais o conceito de mediador ensina que:

O mediador é "o terceiro interventor que, mediante técnicas apropriadas ligadas à negociação, dirige as partes para uma solução de valor mútuo. Sua intervenção é neutra e de certa forma limitada, porque sua autoridade está voltada para o processo propriamente dito, e não para a substância da disputa.

Também na Resolução no 125 , de 29 de novembro de 2010, do Conselho Nacional de Justiça (CONSELHO NACIONAL DE JUSTIÇA, 2016), encontramos as regras e técnicas de conciliação e mediação. São normas de conduta a serem observadas pelos conciliadores para o bom desenvolvimento do procedimento do ato, permitindo que haja o engajamento dos envolvidos, com vistas à sua pacificação e ao comprometimento com eventual acordo obtido. São elas:

1. Informação: dever de esclarecer os envolvidos sobre o método de trabalho a ser empregado, apresentando-o de forma completa, clara e precisa, informando sobre os princípios deontológicos referidos no Capítulo I, as regras de conduta e as etapas do processo;

2. Autonomia da vontade: dever de respeitar os diferentes pontos de vista dos envolvidos, assegurando-lhes que cheguem a uma decisão voluntária e não coercitiva, com liberdade para tomar as próprias decisões durante ou ao final do processo e de interrompê-lo a qualquer momento; 
3. Ausência de obrigação de resultado: dever de não forçar um acordo e de não tomar decisões pelos envolvidos, podendo, quando muito, no caso da conciliação, criar opções, que podem ou não ser acolhidas por eles;

4. Desvinculação da profissão de origem: dever de esclarecer aos envolvidos que atuam desvinculados de sua profissão de origem, informando que, caso seja necessária orientação ou aconselhamento afetos a qualquer área do conhecimento poderá ser convocado para a sessão o profissional respectivo, desde que com o consentimento de todos;

5. Compreensão quanto à conciliação: Dever de assegurar que os envolvidos, ao chegarem a um acordo, compreendam perfeitamente suas disposições, que devem ser exequíveis, gerando o comprometimento com seu cumprimento.

Já pelas técnicas de conciliação e mediação é possível conduzir as sessões de maneira mais dinâmica, proporcionando às partes iguais oportunidades de manifestação através do uso adequado e regrado do diálogo, superando momentos de intransigência, propiciando a construção de um resultado satisfatório para ambas as partes. Neste sentido, interessante as experiências que surgiram pelos Juizados Especiais do nosso País, donde se destaca a observação das seguintes técnicas:

1. O espaço físico: maneira de organização do local onde será realizada a sessão de conciliação em muito contribui para sua condução. Orienta-se o uso de uma mesa redonda, ou a colocação das cadeiras de modo igualitário, para que o conciliador fique equidistante das partes, evitando que alguma das pessoas que participam da sessão possa ocupar lugar de destaque em relação à outra;

2. A forma de tratamento: todas as partes envolvidas na conciliação devem ser tratadas de maneira respeitosa. O conciliador deve cumprimentar as partes tentando fazer com que se sintam calmas e confortáveis, procurando chamar as pessoas pelo nome, podendo, inclusive, perguntar o modo como gostam de ser chamadas. Estabelecer uma relação de confiança com os envolvidos em muito contribui para o êxito da condução da sessão de conciliação. Entretanto, deve-se evitar conversar em demasia, mantendo-se sempre certo grau de objetividade;

3. O início da sessão de conciliação: a abertura da sessão de conciliação é determinante para nortear seu desenvolver. É imprescindível que o conciliador explique às partes o que é o Juizado de Conciliação, qual a sua função enquanto conciliador, qual é objetivo daquela sessão e como ela se desenvolve. Jamais deve esquecer de fixar as regras que deverão ser seguidas durante a sessão, evitando, assim, a impossibilidade da sua condução e controle, podendo a qualquer tempo reforçar sua observância ou suspender a sessão caso haja constante descumprimento. Além das regras, é conveniente que o conciliador assegure o sigilo do que for 
relatado na sessão, podendo, ainda, dirigir algumas palavras de encorajamento às partes, lembrando que os conflitos são naturais ás relações humanas, podendo, inclusive, elencar algumas das vantagens de se tentar a conciliação. O tom da sessão será definido pela maneira como o conciliador irá iniciá-la;

3. Cada um fala de uma vez: essa é uma das regras indispensáveis para que se possibilite um espaço propício ao diálogo. Isso deve ser esclarecido e combinado já no início da sessão, assegurando que cada uma das partes terá oportunidade de falar e de ser ouvida;

5. Ouvir com empatia: é importante que o conciliador ouça as partes com atenção, dando a devida importância ao que é vivenciado por elas e relatado na sessão de conciliação. Entretanto, para adquirir a confiança das partes, não basta dizer que ouve, sendo imprescindível demonstrar que entende a situação por elas vivenciada. A empatia auxilia no processo de compreensão da situação, criando diferentes pontos de referência a partir da condição onde se situa o outro, respeitando e valorizando seu modo de ver e analisar a realidade, levando a uma melhor interação entre os sujeitos da conciliação;

6. Linguagem não verbal: a condução da sessão de conciliação é marcada pela oralidade. Entretanto, além da fala, outros comportamentos interferem na maneira como o conciliador conduz a sessão de conciliação. Ele deve estar atento às reações positivas ou negativas das partes, aos seus gestos, seu olhar ou tom de voz. Se bem utilizada, a linguagem corporal poderá ser uma boa aliada na condução da sessão de conciliação. Com seu uso, podemse evitar repetições desnecessárias ou situações desagradáveis, substituindo, por exemplo, a constante chamada de atenção por gestos com a mão, sinalizando que a parte espere a sua vez de falar. O tom da voz ajuda a estabelecer o ritmo da sessão. Por intermédio do olhar é possível ao conciliador revelar ou não sua imparcialidade, sua confiabilidade e a importância que dá ás pessoas e às situações por elas vivenciadas;

7. Evitar preconceitos: a imparcialidade é um dos requisitos para a boa condução da sessão de conciliação. Assim, o conciliador deve evitar proferir julgamentos sobre o que é relatado, procurando valorizar igualmente o que é dito pelas partes. O modo como as partes se vestem, como falam e se expressam pode fazer com que se adotem posturas parciais. Os prejulgamentos podem configurar obstáculos ao ouvir e ao exame das questões relatadas, comprometendo a condução imparcial da sessão de conciliação;

8. Fragmentar questões: é comum que as pessoas envolvidas num conflito aglutinem questões, sentimentos e interesses, criando uma grande questão que lhes parece extremamente complexa e insuperável. Ao fragmentar essa grande questão em questões menores o conciliador torna mais fácil e acessível seu exame e resolução. Isso faz com que as partes se sintam mais 
aliviadas e possam, até mesmo, identificar interesses comuns. À medida que solucionam as questões menores (fragmentadas), as partes adquirem autoconfiança e estímulo para trabalhem a questão principal. O conciliador, ao longo da sessão, poderá reforçar o que foi conseguido, valorizando o esforço de cada uma das partes, estimulando-a a continuar contribuindo para o resultado final; e

9. Não multiplicar além da necessidade: o conciliador deve enfatizar somente o que for essencial para os fins da conciliação, buscando apenas as informações necessárias à compreensão dos pontos controvertidos, evitando questionamentos vagos ou com objetivo de satisfazer sua curiosidade. O conciliador atua como um filtro das informações, enfatizando os pontos relevantes para o esclarecimento da questão, para a melhor compreensão recíproca e para a escolha das alternativas adequadas. No momento da redação do acordo, o conciliador deve lembrar dessa técnica, procurando ser objetivo, claro e preciso, não esquecendo de registrar o necessário à satisfação do acordo.

Os psicoterapeutas londrinos Penny Tompkins e James Lawley (2016) citam ainda a técnica do rapport, que significa "receptividade ao que o outro está dizendo; não necessariamente que você concorde com o que está sendo dito. Você e os outros sentem que são escutados e ouvidos". André Gomma Azevedo (2009. p. 135-149), trilhando pelo mesmo caminho, dita que o rapport "é uma forma de ganhar a confiança das partes por meio de um diálogo aberto e construtivo para o fim de influenciar os interessados a chegarem a autocomposição", pois todas partes se sentem seguras quando são ouvidas na sua versão.

Destarte, as regras e técnicas de mediação e conciliação proporcionam ao facilitador melhores condições de conseguir o seu desiderato, qual seja: harmonizar os interesses e alcançar a pacificação social, que é o fim último do objetivo desses institutos.

\section{A CONCILIAÇÃo E A MEDIAÇÃo NO DIREITO DE FAMÍLIA}

Como já explanado anteriormente, o facilitador terá que vencer a emoção e a paixão das partes, em se tratando de conflito familiar. Destarte, no direito de família, notadamente a mediação, tem como objetivo a pacificação do conflito familiar, sem perder de vista a finalidade de despertar a responsabilidade das partes e dos operadores do direito na reorganização familiar, com novo significado para a questão posta e posterior convivência.

José Herval Sampaio Júnior (2015) bem observa que:

Nas relações familiares, a intensidade e complicações dos sentimentos e emoções são bem maiores do que em outros relacionamentos, sendo quase impossível que não haja conflitos. No entanto, o grande entrave consiste na supervalorização desses conflitos, dos sentimentos egoístas e do orgulho existente entre as partes, dificultando a composição do conflito. 
Destarte, a figura do mediador familiar deve ser diferente. Deve estar preparado também emocionalmente e não apenas tecnicamente, devendo agir preventivamente e, caso haja necessidade, após a separação, como amparo aos envolvidos para a nova situação que se apresenta. Desse modo, importante citar os ensinamentos de Haim Grunspun (2015), que define mediador familiar como sendo:

Um profissional que atua de forma voluntária para chegar estrategicamente a um acordo entre casais que buscam a mediação de forma voluntária. Sua ação é na comunidade e pode intervir em famílias íntegras em via de separação agindo de forma preventiva, pode agir durante a separação ou após a separação quando surgem problemas para criar e educar os filhos nas novas formas de família.

Dessa forma, o facilitador deve ter um cuidado redobrado em casos tais, observando regras e técnicas para a pacificação do conflito, causando menos desgaste aos envolvidos. Vale relembrar aqui que em sede de litígios de família, os conflitos não terminam com a solução lançada para o caso concreto, mas se perduram por longos anos, como é o caso dos filhos, cujo laço não se romperá, ainda que haja a separação dos pais. Na verdade as relações familiares só se encerram quando se parte desta vida terrena.

\section{A CONCILIAÇÃo NO NOVO CÓDIGO DE PROCESSO CIVIL:}

O novo Código de Processo Civil (Lei n ${ }^{\circ} 13.105$, de 16 de março de 2015), que entrará em vigor no mês de março de 2016, destinou vários dispositivos à conciliação e mediação.

Prevê tal Código, no artigo 334, uma audiência de conciliação ou mediação como regra, salvo se as partes se manifestarem expressamente em sentido contrário. Dita tal dispositivo:

Art. 334. Se a petição inicial preencher os requisitos essenciais e não for o caso de improcedência liminar do pedido, o juiz designará audiência de conciliação ou de mediação com antecedência mínima de 30 (trinta) dias, devendo ser citado o réu com pelo menos 20 (vinte) dias de antecedência.

$\S 1^{\circ}$ - O conciliador ou mediador, onde houver, atuará necessariamente na audiência de conciliação ou de mediação, observando o disposto neste Código, bem como as disposições da lei de organização judiciária.

$\S 2^{\circ}$ - Poderá haver mais de uma sessão destinada à conciliação e à mediação, não podendo exceder a 2 (dois) meses da data de realização da primeira sessão, desde que necessárias à composição das partes.

$\S 3^{\circ}$ - A intimação do autor para a audiência será feita na pessoa de seu advogado.

$\S 4^{\circ}$ - A audiência não será realizada:

I - se ambas as partes manifestarem, expressamente, desinteresse na composição consensual;

II - quando não se admitir a autocomposição.

$\S-5^{\circ} \mathrm{O}$ autor deverá indicar, na petição inicial, seu desinteresse na autocomposição e o réu deverá fazê-lo, por petição, apresentada com 10 (dez) dias de antecedência, contados da data da audiência.

$\S 6^{\circ}$ - Havendo litisconsórcio, o desinteresse na realização da audiência deve ser manifestado por todos os litisconsortes.

$\S 7^{\circ}$ - A audiência de conciliação ou de mediação pode realizar-se por meio eletrônico, nos termos da lei. 
$\S 8^{\circ}$ - O não comparecimento injustificado do autor ou do réu à audiência de conciliação é considerado ato atentatório à dignidade da justiça e será sancionado com multa de até dois por cento da vantagem econômica pretendida ou do valor da causa, revertida em favor da União ou do Estado.

$\S 9^{\circ}$ - As partes devem estar acompanhadas por seus advogados ou defensores públicos.

$\S 10$ - A parte poderá constituir representante, por meio de procuração específica, com poderes para negociar e transigir.

$\S 11$ - A autocomposição obtida será reduzida a termo e homologada por sentença.

$\S 12$ - A pauta das audiências de conciliação ou de mediação será organizada de modo a respeitar o intervalo mínimo de 20 (vinte) minutos entre o início de uma e o início da seguinte.

Ainda, na audiência de instrução e julgamento, "ab initio", o juiz tentará conciliar as partes, independentemente do fato de que outros métodos de solução consensual de conflitos, como a mediação e a arbitragem, tenham sido adotados anteriormente (artigo 359, do novo $\left.\mathrm{CPC}^{8}\right)$.

Nas ações de família propriamente ditas, houve uma preocupação destacada do legislador, com relação a conciliação e mediação. O artigo 694 do novel Código de Processo Civil destaca que nas ações de família deverão ser empreendidos todos os esforços possíveis para a solução consensual da controvérsia, devendo o juiz valer-se do auxílio de profissionais em outras áreas de conhecimento para a mediação e conciliação ${ }^{9}$. O legislador autoriza o juiz, inclusive, a dividir as seções de conciliação e mediação em tantas quantas sejam necessárias para viabilizar a solução consensual, sem prejuízo de providências jurisdicionais para evitar o perecimento do direito ${ }^{10} \mathrm{e}$, somente após a tentativa infrutífera de acordo, passarão a incidir as normas do procedimento comum ${ }^{11}$.

Por fim, neste sentido, criou o legislador uma seção para tratar dos conciliadores e mediadores judiciais (Seção V - Dos Conciliadores e Mediadores Judiciais - artigos 164 a 175, do novo CPC).

Os juristas Jorge Amaury Maia Nunes e Guilherme Pupe da Nóbrega (apud SANDER, 1976), asseveram que Frank Sander, professor de Harvard que em 1976 proferiu discurso na "Roscoe Pound Confference" sobre a insatisfação popular com a administração da justiça

\footnotetext{
${ }^{8}$ Art. 359. Instalada a audiência, o juiz tentará conciliar as partes, independentemente do emprego anterior de outros métodos de solução consensual de conflitos, como a mediação e a arbitragem.

${ }^{9}$ Art. 694. Nas ações de família, todos os esforços serão empreendidos para a solução consensual da controvérsia, devendo o juiz dispor do auxílio de profissionais de outras áreas de conhecimento para a mediação e conciliação. Parágrafo único. A requerimento das partes, o juiz pode determinar a suspensão do processo enquanto os litigantes se submetem a mediação extrajudicial ou a atendimento multidisciplinar.

${ }^{10}$ Art. 696. A audiência de mediação e conciliação poderá dividir-se em tantas sessões quantas sejam necessárias para viabilizar a solução consensual, sem prejuízo de providências jurisdicionais para evitar o perecimento do direito.

11 Art. 697. Não realizado o acordo, passarão a incidir, a partir de então, as normas do procedimento comum, observado o art. 335.
} 
intitulado "Varieties of dispute processing" e, ao comentar essa nova perspectiva do CPC de 2015, disse tratar-se do sistema chamado multiportas, onde se tem que, sendo várias as veredas possíveis rumo à solução do conflito, deve o Judiciário, sim, ser o meio alternativo, subsidiário para dirimir controvérsias.

\section{CENTROS JUdiciários DE SOLUÇÃO DE CONFLITOS E CIDADANIA - CEJUSCs}

Dentro desse contexto - conciliação e mediação como solução de conflitos -, o Conselho Nacional de Justiça deu um importante passo para estimular a mediação e a conciliação, ao editar a Resolução $\mathrm{n}^{\circ} 125$, de 29 de novembro de 2010, instituindo a Política Judiciária Nacional de tratamento aos conflitos de interesses. E, dentre os mecanismos de soluções de controvérsias a que incumbiu os órgãos judiciários (em especial os meios consensuais, como a mediação e a conciliação), determinou aos Tribunais a criação dos Centros Judiciários de Solução de Conflitos e Cidadania, conhecidos como os CEJUSCs, incumbidos de realizarem as sessões de conciliação e mediação pré-processuais, cujas audiências são realizadas por conciliadores e mediadores credenciados junto ao Tribunal respectivo. E, em cumprimento a tal Resolução, o Tribunal de Justiça do Estado do Paraná editou a Resolução no 02/2014, onde regula o funcionamento dos Centros Judiciários de Solução de Conflitos e Cidadania - CEJUSCs no Estado ${ }^{12}$, para atender, inicialmente, conflitos de direitos patrimoniais disponíveis de competência dos Juizados Especiais e Varas Cíveis da Justiça Estadual, além dos de competência das Varas de Família relacionados à fixação de alimentos, guarda, direito de visitas, divórcio e separação por exemplo.

Se ainda não existir Ação (fase pré-processual) a parte interessada na tentativa de solução de conflitos por meio da mediação poderá ir até o Centro, munida da documentação pessoal, para passar pela triagem do caso, quando o servidor irá verificar a possibilidade de que sejam utilizados os métodos alternativos. Neste caso será designada audiência. Se existir um Processo Cível ajuizado, as partes ou seus procuradores podem pedir ao juízo onde a Ação tramita, por meio de uma petição, seu encaminhamento para o Centro, a fim de que seja realizada audiência de mediação. Os magistrados também podem encaminhar os processos de ofício quando vislumbrarem a possibilidade de que as partes entrem em acordo após atendimento individualizado e qualificado.

${ }^{12}$ É uma ferramenta à disposição da população que utiliza métodos alternativos de solução de conflitos como a mediação e conciliação. Por meio do CEJUSC os envolvidos têm a chance de conversar e entre si realizar a autocomposição do litígio. A audiência é realizada por um Mediador em treinamento pelo Conselho Nacional de Justiça (CNJ) ou Conciliadores e o acordo, homologado por Juiz de Direito, tem força de título executivo judicial. 
É de se destacar ainda que o novo Código de Processo Civil absorveu a ideia do Conselho Nacional de Justiça no intuito de estimular o que este chamou de "Cultura da Paz", trazendo no texto aprovado, grande destaque para a Mediação e Conciliação ${ }^{13}$, como já salientado.

\section{JUIZADOS ESPECIAIS DE FAMÍLIA}

Outra alternativa apresentada pelo legislativo, dentro da ideia da conciliação e mediação como solução de conflitos, foi o PL 230/10, do Senador Acir Gurgacz, que prevê a criação dos Juizados Especiais de família, cuja competência resta firmada pelos artigos $2^{\circ}$ e $5^{\circ}$, que dita:

Art. $2^{\circ}$ - As ações de investigação de paternidade; de separação judicial; de fixação de alimentos, revisão e exoneração; de divórcio; de regulamentação de visita; de separação de corpos; de guarda de filhos, bem como outras atinentes ao Direito de Família, por opção do autor, poderão ser submetidas ao rito sumaríssimo da Lei n. ${ }^{\circ}$ 9.099/95.

Art. $5^{\circ} \mathrm{O}$ Juizado Especial de Família tem competência para conciliação, processo e julgamento das causas de família cujo patrimônio não exceda a um imóvel.

Já o artigo $3^{\circ}$ do PL em alusão, determina que a mediação, conduzida por equipe multidisciplinar, com o objetivo de sensibilização das partes, deverá preceder a todos os atos, inclusive a conciliação ${ }^{14}$.

A ministra do Superior Tribunal de Justiça (STJ) Fátima Nancy Andrighi (2015), referindo-se ao tema aqui tratado, disse que:

A experiência evidencia que, nos conflitos de família, em que as partes apenas querem resolver as questões e precisam estabelecer suas relações futuras por causa dos filhos, o processo tradicional, adversarial, termina por estimular as partes a se tornarem adversárias, transformando-se em instrumento de vindita, de obstinação, eis que cada uma das partes se coloca em posição de defesa, fincando raiz no seu ponto de vista. Dessa forma, impõe-se que o juiz se conscientize da verdadeira postura a ser adotada diante dos conflitos de família, devendo o seu perfil ser de pacificador, de serenador das almas, despindo-se, ao máximo, da postura moralista ou apenas crítica e proporcionando ao casal em conflito a humanização desta arena conflituosa. $\mathrm{O}$ ambiente, assim, tem que levar ao diálogo amistoso e não à separação conflituosa.

Se partirmos de experiências que já deram certo, neste sentido, como os Juizados Especiais, Cíveis, Criminais, da Fazenda Pública e da Justiça Federal, sem perder de vista os meios de solução consensual de conflitos ali existentes, com as inovações advindas nesta seara,

13 Art. 165. Os tribunais criarão centros judiciários de solução consensual de conflitos, responsáveis pela realização de sessões e audiências de conciliação e mediação e pelo desenvolvimento de programas destinados a auxiliar, orientar e estimular a autocomposição.

$\S 1^{\circ}$ - A composição e a organização dos centros serão definidas pelo respectivo tribunal, observadas as normas do Conselho Nacional de Justiça.

${ }^{14}$ Art. $3^{\circ}$ A conciliação será antecedida por mediação conduzida por equipe multidisciplinar, que fará trabalho de sensibilização das partes. Parágrafo Único - A conciliação será conduzida pelo juiz togado ou leigo, ou por conciliador, sob sua orientação. 
certamente os Juizados Especiais de Família contribuirão para a melhor solução dos conflitos e apaziguamento social. Tudo, sem perder de vista a necessária participação do Estado na estruturação necessária, notadamente no que diz respeito aos meios físicos e preparação dos facilitadores, inclusive com remuneração digna, sob pena de se transformar a ideia em "letra morta".

\section{CONCLUSÃo}

O presente artigo buscou demonstrar que o Acesso à Justiça, como direito fundamental e princípio constitucional, não se perfectibiliza apenas com o fato de se estar em Juízo, mas que a prestação jurisdicional seja efetiva e tempestiva, com o apaziguamento social. E, para tal fim, a conciliação e a mediação - notadamente em conflitos que envolvem questões familiares - se apresentam como instrumentos de solução de conflitos adequados, uma vez que, diante de técnicas e preparação dos facilitadores, resolvem a questão da melhor maneira possível, possibilitando a posterior convivência entre as partes, vencendo a paixão e a emoção que normalmente impera nos conflitos familiares, buscando-se a solução também pela razão.

Dos princípios, regras e técnicas aqui apresentados pode se extrair justamente a possibilidade acima aventada, pois clara a preocupação não apenas em solucionar o problema, mas também com o apaziguamento das partes. Busca-se, enfim, a harmonia familiar, tão importante na vida social.

Demostrou-se também a preocupação do Estado, de uma maneira geral, em propiciar a todos os jurisdicionados a prévia mediação e conciliação, valendo-se o processo apenas para os casos em que restarem infrutíferas as soluções por tais meios. E o novo Código de Processo Civil que entrou em vigência em 18.03.2106, deixa clara a preocupação do legislador neste sentido.

É certo, porém, que sem uma estrutura física compatível, sem um preparo dos facilitadores em cursos específicos, de nada adianta as modificações elencadas pela nova legislação processual. O Estado deverá proporcionar meios adequados para que a mediação e conciliação possam ser levadas a efeitos nos moldes idealizados, tais como propiciar o mínimo de suporte material, estímulo, treinamento, inclusive com a previsão de remuneração dos mediadores e conciliadores, sob pena de perecer todo o esforço legislativo até então empreendido.

De qualquer sorte, o primeiro passo já foi dado. Muito já foi feito. A caminhada histórica neste sentido revela o grande desenvolvimento nesta seara, desde as primeiras intervenções. O que não pode ocorrer é justamente o retrocesso, havendo a necessidade de 
direcionamento de programas governamentais acompanhando essa flecha direcionadora já disparada, rumo a seu alvo, no sentido de se reduzir as longas e complexas demandas judiciais ao mínimo possível, para que possa também ter celeridade e obter a tal almejada decisão da Justiça.

\section{REFERÊNCIAS}

ANDRIGHI, Fátima Nancy. JUIZADO ESPECIAL DE FAMÍLIA. Disponível em: <file:///C:/Users/hlc/Documents/tempor\%C3\%A1 rio/05102001 fatimanancyjuizadofamilia.pdf $>$. Acesso em: 15 dez. 2015.

ASSIS, Araken de. Processo Civil Brasileiro, volume I: parte Geral: fundamentos e distribuição de conflitos. São Paulo: Editora Revista dos Tribunais, 2015.

AZEVEDO, André Gomma (Org.). Manual de Mediação Judicial. Brasília: Ministério da Justiça e Programa das Nações Unidas para o Desenvolvimento - PNUD, 2009.

BACELLAR, Roberto Portugal. Mediação e arbitragem: coleção saberes do direito. São Paulo: Saraiva, 2012.

BRASIL. Conselho Nacional de Justiça. Disponível em: <http://www.cnj.jus.br/busca-atosadm?documento=2579>. Acesso em: 28 mar. 2016.

BRASIL. Presidência da República. Casa Civil. II Pacto Republicano de Estado por um Sistema de Justiça mais Acessível, Ágil e Efetivo. Disponível em: <http://www.planalto.gov.br/ccivil_03/Outros/IIpacto.htm>. Acesso em: 28 mar. 2016.

BUENO, Tayna Xavier Arantes. Entre as medidas alternativas de solução de litígios do Poder Judiciário: a conciliação. Disponível em:

<http://www.ambitojuridico.com.br/site/?n_link=revista_artigosleitura\&artigo_id=13412>. Acesso em: 28 mar. 2016.

CUNHA, Lukenya Laize Silva da e SILVA, Regilene Ferreira da (apud PINTO, A. da C. Psicologia Geral. Lisboa: Universidade Aberta. 2001). Emoções: uma construção reflexiva. Disponível em: <https://psicologado.com/psicologia-geral/introducao/emocoes-umaconstrucao-reflexiva>. Acesso em: 28 mar. 2016.

DOMINGUES FILHO, José. Roteiro das Audiências Cíveis. 2.ed. Campo Grande: Contemplar, 2016.

FISS, Owen M. Um Novo Processo Civil. Estudos Norte-Americanos sobre Jurisdição, Constituição e Sociedade. São Paulo: Editora Revista dos Tribunais, 2004.

GRUNSUN, Haim. Mediação Familiar: o mediador e a separação de casais com filhos. Disponível em: <http://www.revistapsicologia.com.br/materias/entrevistaAutor/mediador_familiar.htm>. Acesso em: 15 dez. 2015. 
HOLANDA, Aurelio Buarque. Míni Dicionário Aurélio da Língua Portuguesa. 8.ed. São Paulo: Positivo Editora, 2010.

. Novo Dicionário Aurélio da Língua Portuguesa. 3.ed. São Paulo: Positivo Editora, 2004.

HUNGRIA, Nelson. Comentários ao Código Penal. v.1. Rio de janeiro: Ed. Revista Forense, 1949.

JÚNIOR, Enéas Castilho Chiarini. A mediação no direito de família. Disponível em: $<$ http://www.ambito-

juridico.com.br/site/index.php?n_link=revista_artigos_leitura\&artigo_id=3767>. Acesso em: 15 dez. 2015.

MELLO, Celso Antônio Bandeira de. Elementos de direito administrativo. São Paulo: Editora Revista dos Tribunais, 1991.

NUNES, Jorge Amaury Maia e NÓBREA, Guilherme Pupe da (apud SANDER, Frank E.A. Varieties of Dispute Processing. In: The Pound Conference. 70 Federal Rules Decisions 111, 1976). Processo e Procedimento. Disponível em:

<http://www.migalhas.com.br/ProcessoeProcedimento/106,MI225789,41046-

A+audiencia+de+conciliacao++de+mediação+no+CPC2015>. Acesso em: 18 mar. 2016.

PEDROSO, Fernando A. Homicídio - participação em suicídio-infanticídio e aborto. São Paulo, Aido, 1995.

RUIZ, Ivan Aparecido. A autocomposição nas relações de família. Revista Jurídica Cesumar, v.5. Maringá, 2005.

SAMPAIO JÚNIOR, José Herval. O papel do juiz na tentativa de pacificação social: a importância das técnicas de conciliação e mediação. Revista Direito e Liberdade, Mossoró, v. 6, n. 1, p. 147-174, jan./jun. 2007. Disponível em:

<http://mossoro.esmarn.org.br/revista_direito_liberdade/edicoes/Revista_Direito_e_Liberdad e_volume_6.pdf>. Acesso em: 15 dez. 2015.

SERPA, Maria de Nazareth. Mediação, processo judicioso e resolução de conflitos. Belo Horizonte: Faculdade de Direito. UFMG, 1997.

SILVA, João Roberto da. Arbitragem - Aspectos Gerais da Lei 9307/96. São Paulo: Mizuno, 2004.

TOMPKINS, Penny; LAWNEY, James. Rapport: o ingrediente mágico. Disponível em: <http://golfinho.com.br/artigo/rapport-o-ingrediente-magico.htm>. Acesso em: 28 mar. 2016.

TURA, Adevanir. Arbitragem - Nacional e Internacional. São Paulo: Editora JH Mizuno, 2007.

VIEIRA, Marina Nunes. Conciliação: simples e rápida solução de conflitos. Disponível em: <http://blog.newtonpaiva.br/direito/wp-content/uploads/2012/08/PDF-D13-05.pdf>. Acesso em: 28 mar. 2016. 